\title{
Compactação do solo em sistemas de integração lavoura-pecuária- floresta após cinco anos de implantação e uso
}

\author{
Soil compaction in crop-livestock-forest integration systems of five years of implantation \\ and use
}
Jéssica Fernanda Dias Souza ${ }^{1}$, Carolina dos Santos Batista Bonini ${ }^{1 *}$, Gustavo Pavan Mateus ${ }^{2}$, Caroline Teodoro de Souza ${ }^{1}$, Rafael Luís Sanchez Perusso ${ }^{1}$, Fabricio Gomes Pedro ${ }^{1}$, Gabriela Lozano Oliverio $^{1}$

${ }^{1}$ Faculdade de Ciências Agrárias e Tecnológicas, Dracena, SP, Brasil. *Autor para correspondência: carolina.bonini@unesp.br

${ }^{2}$ Agência Paulista de Tecnologia dos Agronegócios, Andradina, SP, Brasil.

Submissão: 19/06/2019 / Aceite: 22/06/2020

\begin{abstract}
RESUMO
O objetivo deste trabalho foi analisar os atributos físicos de um Latossolo Vermelho Amarelo de diferentes sistemas de integração lavoura-pecuária-floresta implantados em 2012 e em uso desde então. O delineamento experimental utilizado foi em blocos casualizados, com quatro repetições e quatro tratamentos: ILP - integração lavoura-pecuária; ILPF 1L - sistema agrossilvipastoril, com uma linha de eucalipto; ILPF 3L - sistema agrossilvipastoril, com três linhas de eucalipto; e EUC - plantio exclusivo de eucalipto (bosque). No período de junho de 2017 a maio de 2018 foram realizadas avaliações da resistência mecânica à penetração e da umidade gravimétrica do solo, a fim de monitorar a compactação, em três camadas do solo: 0-0,05; 0,05-0,10 e 0,10-0,20 m de profundidade. Os resultados mostram que houve diferença significativa para os atributos do solo estudados, sendo a maior compactação encontrada no tratamento ILPF $3 \mathrm{~L}(0,05-0,10 \mathrm{~m})$ próximo ao limite considerado ideal para um bom desenvolvimento das plantas. A umidade gravimétrica do solo não influenciou os resultados de compactação. De modo geral, os resultados mostram que a presença dos animais não causa uma compactação muito drástica ao solo, com valores menores que o limite crítico de $2 \mathrm{MPa}$.
\end{abstract}

PALAVRAS-CHAVE: atributos físicos do solo, sustentabilidade, resistência mecânica à penetração.

\begin{abstract}
The objective of this work was to analyze the physical attributes of a Oxisol of different crop-livestockforest integration systems implanted in 2012 and in use since then. The experimental design was a randomized complete block design, with four replications and four treatments: ILP - crop - livestock integration; ILPF 1L - agrosilvopastoral system, with one eucalyptus line; ILPF 3L - agrosilvopastoral system, with three eucalyptus lines; and EUC - exclusive plantation of eucalyptus (forest). From June 2017 to May 2018, mechanical penetration and gravimetric soil moisture evaluations were carried out to monitor soil compaction in three depths of soil: $0-0.05 ; 0.05-0.10$ and $0.10-0.20 \mathrm{~m}$. The results of the research show that there was a significant difference in the soil attributes studied, being the highest compaction found in the treatment ILPF $3 \mathrm{~L}(0.05-0.10 \mathrm{~m})$ near the limit considered ideal for a good development of the plants. Gravimetric soil moisture did not influence compaction results. In general, the results show that in the soil conditions of the region considered fragile and highly susceptible to compaction, the presence of the animals does not cause a very drastic compaction to the soil, with values lower than the critical limit of $2 \mathrm{MPa}$.
\end{abstract}

KEYWORDS: soil physical attributes, sustainability, mechanical resistance to penetration.

A gestão adequada dos solos agrícolas é uma preocupação primordial para a agricultura sustentável, porque o sistema de produção afeta significativamente as propriedades físicas, químicas e biológicas do solo e, por consequência, a produtividade das culturas agrícolas (SILVA et al. 2015). Sistemas conservacionistas de produção agrícola, como os sistemas integrados de produção agropecuária (SIPAs), consórcio de culturas, rotação de culturas, sistema de semeadura direta (SSD) e manejo adequado de pastagens, podem contribuir para a descompactação do solo - um dos grandes problemas da degradação, 
melhorando o ambiente para o desenvolvimento das culturas na área agrícola (COSTA et al. 2015).

O monitoramento periódico do estado de compactação do solo por meio da resistência à penetração é uma forma prática de avaliação dos efeitos dos diferentes sistemas de manejo na estrutura do solo e do crescimento radicular das culturas (TAVARES FILHO \& RIBON 2008). Outro ponto importante é a determinação da umidade do solo no momento da avaliação da resistência do solo à penetração (BONINI \& ALVES 2012), para se realizar adequadamente a interpretação dos resultados encontrados, pois solos muito secos podem ter maior resistência à penetração devido as forças de coesão do solo, e solos muito úmidos a resistência pode ser nula pois as forças atuantes serão somente das moléculas de água que predominam no solo.

A resistência mecânica à penetração é indicativa de degradação e, o efeito dessa condição causa um impedimento ao crescimento do sistema radicular das plantas devido à restrição de água, nutrientes, ar e espaço para sua expansão (PIGNATARO NETTO et al. 2009), além de influenciar na infiltração e distribuição da água no solo (TAVARES FILHO et al. 2005). Uma das principais causas da degradação em áreas cultivadas é a compactação do solo, causada pelo tráfego de máquinas, implementos agrícolas e pisoteio animal em áreas de integração lavoura-pecuária (REICHERT et al. 2007). Em sistema de integração lavoura-pecuária, o pisoteio animal tem sido apontado como uma das principais causas da degradação de áreas cultivadas (ALBUQUERQUE et al. 2001), afetando principalmente a camada superficial do solo (nos primeiros $150 \mathrm{~mm}$ de profundidade) (GREENWOOD \& MCKENZIE 2001, LANZANOVA et al. 2007).

Entre as estratégias agrícolas que tendem a contribuir para o aumento da sustentabilidade dos sistemas agrícolas, destacam-se os sistemas agrossilvipastoris, que integram atividades agrícolas, pecuárias e florestais (BALBINO et al. 2011). Segundo KLUTHCOUSKI et al. (2015), as SIPAs em conjunto com o plantio direto merecem destaque nesse contexto (principalmente em solos de extrema fragilidade, como os arenosos, visto que possibilita a manutenção e, ou, melhoria nos atributos físicos, químicos e biológicos do solo.

Várias pesquisas para monitorar a compactação foram realizadas para verificar os efeitos da compactação em SIPAs, mas a maioria em solos argilosos (MARCHÃO 2007, LIMA et al. 2010, MENEZES et al. 2013, SANTANA et al. 2014), em solos arenosos e frágeis são poucos os trabalhos encontrados (SÁ et al. 2007, MARCHÃO et al. 2009, BONINI et al. 2016). Dessa forma, o objetivo deste trabalho foi avaliar a compactação do solo em sistemas integrados de produção agropecuária após cinco anos de implantação e uso, além de verificar o efeito do pisoteio animal na qualidade física do solo.

O experimento foi desenvolvido em área experimental do Polo Regional de Desenvolvimento Tecnológico dos Agronegócios do Extremo Oeste, sediado no município de Andradina, SP, localizado na região noroeste do Estado de São Paulo (2055'S; 51 $23^{\circ} \mathrm{W}$; $379 \mathrm{~m}$ de altitude, Aw). O solo em estudo é um Latossolo Vermelho Amarelo distrófico (SANTOS et al. 2018).

As avaliações foram realizadas em uma área de 27 ha onde estavam implantados os sistemas ILPF, desde julho de 2012. No momento da implantação do experimento foi realizada a caracterização física do solo, com $765 \mathrm{~g} \mathrm{~kg}^{-1}$ de areia, $116 \mathrm{~g} \mathrm{~kg}^{-1}$ de argila e $119 \mathrm{~g} \mathrm{~kg}^{-1}$ de silte (BONINI et al. 2016). Para a implantação o solo da área foi corrigido e foram realizadas operações mecanizadas (gradagem aradora, aração e gradagem niveladora) no preparo da área experimental.

O delineamento experimental utilizado foi em blocos casualizados, com quatro repetições, sendo os tratamentos: ILP - integração lavoura-pecuária, sem o componente arbóreo; ILPF 1L - sistema agrossilvipastoril, com sombreamento de uma linha de eucalipto, sendo a distância entre cada linha 17 a 21 $\mathrm{m}$ e a distância entre plantas de $2 \mathrm{~m}$, com densidade de 200 árvores/ha; ILPF $3 \mathrm{~L}$ - sistema agrossilvipastoril, com sombreamento de três linhas de eucalipto, sendo a distância entre as faixas de eucalipto de 17 a $21 \mathrm{~m}$ e a distância entre plantas de $2 \mathrm{~m}$, com densidade de 500 árvores/ha; EUC - plantio exclusivo de eucalipto (bosque).

O plantio do eucalipto (clone I-224) foi realizado no início de 2013, e realizada a adubação de plantio (350 kg ha ${ }^{-1}$ da fórmula 04-30-16 por cova). Na adubação de cobertura $37 \mathrm{~kg} \mathrm{ha}^{-1}$ de nitrogênio (ureia), $3 \mathrm{~kg}$ $\mathrm{ha}^{-1}$ de zinco (sulfato de zinco) e $2 \mathrm{~kg} \mathrm{ha}^{-1}$ de boro (borogran) aplicados na forma de coroa sobre cada muda. Nos sistemas ILP, ILPF1L e ILPF3L, em dezembro de 2013, foi cultivado soja (cultivar BMX potência), com densidade de 20 sementes $\mathrm{m}^{-1}$ e espaçamento de $0,50 \mathrm{~m}$ entrelinhas, totalizando 400.000 sementes ha ${ }^{-1}$. A adubação de semeadura foi de $300 \mathrm{~kg} \mathrm{ha}^{-1}$ do fertilizante 4-30-16 e a adubação de cobertura, realizada 40 dias após o plantio, aplicando $200 \mathrm{~kg} \mathrm{ha}^{-1} 00-20-20$, a fim de elevar os níveis de nutrientes, já que era uma área degradada de pastagem.

$\mathrm{Na}$ safra 2013/2014, foi cultivado milho (híbrido de milho DKB 390) com capim-marandu (Urochloa 
brizantha) cv. Marandu, com espaçamento de 0,80 m entrelinhas e adubação de implantação de $350 \mathrm{~kg} \mathrm{ha}^{-1}$ de 8-28-16 e em cobertura $112 \mathrm{~kg} \mathrm{ha}^{-1}$ nitrogênio (ureia).

A pastagem utilizada foi a de capim-marandu, com densidade de semente de $8,0 \mathrm{~kg} \mathrm{ha}^{-1}$, plantada simultaneamente com o milho com semeadura direta. Após a colheita do milho a área foi dividida em piquetes e a utilização do pasto iniciou em setembro de 2014, quando as plantas de eucalipto completaram 18 meses.

Para monitorar a compactação do solo, foram avaliadas a resistência mecânica à penetração, com o uso do penetroLOG (modelo Falker) e a umidade gravimétrica do solo, por meio do método clássico de pesagem (TEIXEIRA et al. 2017), no momento da realização da resistência do solo à penetração, para maior confiança dos dados obtidos. As avaliações foram realizadas nas camadas de 0-0,05; 0,05-0,10 e 0,10-0,20 m. Os locais de amostragem nos tratamentos com ILPF e bosque, foram realizadas em seis pontos do piquete, nas distâncias de 0, 2, 4, 6, 8 e $10 \mathrm{~m}$ em relação a linha de eucalipto e no sistema ILP em relação a curva de nível central da parcela experimental, com esse esquema de amostragem na parcela experimental os dados obtidos foram mais representativos.

Os dados de resistência à penetração e umidade gravimétrica do solo foram analisados em cada camada de solo estudada (0-0,05; 0,05-0,10 e 0,10-0,20 m), efetuando-se a análise de variância, teste de Scott-Knott a 5\% de significância, por meio do programa estatístico SISVAR (FERREIRA 2011).

Os dados de resistência do solo à penetração e umidade gravimétrica estão apresentados na Tabela 1. Não houve interação entre distância de coleta e tratamentos utilizados. Para resistência à penetração somente na camada de 0,10-0,20 m houve diferença significativa entre os tratamentos. A distância da amostragem interferiu para este atributo na camada de 0,05-0,10 m apresentando maiores valores nas distâncias $0 \mathrm{~m}, 4 \mathrm{~m}, 6 \mathrm{~m}$ e $8 \mathrm{~m}$, sendo que nas distâncias $6 \mathrm{~m}$ e $8 \mathrm{~m}$, mostrando que o gado preferencialmente pastejou nesses locais, por melhor ambiência e oferta de capim. Esse comportamento preferencial por alguns locais no piquete também foi verificado por MARCHÃO et al. (2009) que afirmaram que o pastejo em altas taxas de lotação podem devido ao pisoteio animal excessivo provocar a compactação do solo no local, sendo alarmantes as áreas onde há a necessidade constante de locomoção por buscar água ou alimentos mais palatáveis, por exemplo.

Tabela 1. Valores médios de resistência a penetração de raízes ( $\mathrm{MPa}), \mathrm{F}(5 \%)$ e CV (\%) dos tratamentos e nas camadas de 0,00-0,05; 0,05-0,10 e 0,10-0,20 m. Andradina, SP. 2017.

Table 1. Mean values of root penetration resistance (MPa), $F(5 \%)$ and $\mathrm{CV}(\%)$ of the treatments and in the depths of 0.00-0.05; 0.05-0.10 and 0.10-0.20 m. Andradina, SP. 2017.

\begin{tabular}{lcccccc}
\hline & \multicolumn{3}{c}{$\mathrm{RP}(\mathrm{MPa})$} & $\mathrm{UG}\left(\mathrm{g} \mathrm{g}^{-1}\right)$ & \\
\hline & $0-0,05 \mathrm{~m}$ & $0,05-0,10 \mathrm{~m}$ & $0,10-0,20 \mathrm{~m}$ & $0-0,05 \mathrm{~m}$ & $0,05-0,10 \mathrm{~m}$ & $0,10-0,20 \mathrm{~m}$ \\
\hline BOSQUE & 0,33 & 1,45 & $0,32 \mathrm{~b}$ & $0,02 \mathrm{~b}$ & $0,01 \mathrm{~b}$ & $0,01 \mathrm{~b}$ \\
ILP (Pasto) & 0,38 & 1,83 & $0,95 \mathrm{a}$ & $0,03 \mathrm{a}$ & $0,02 \mathrm{~b}$ & $0,01 \mathrm{~b}$ \\
ILPF 1L & 0,33 & 1,93 & $0,60 \mathrm{~b}$ & $0,03 \mathrm{a}$ & $0,02 \mathrm{~b}$ & $0,04 \mathrm{a}$ \\
ILPF 3L & 0,32 & 2,07 & $1,21 \mathrm{a}$ & $0,04 \mathrm{a}$ & $0,04 \mathrm{a}$ & $0,04 \mathrm{a}$ \\
\hline 0 & 0,22 & $1,84 \mathrm{a}$ & 0,91 & 0,03 & 0,02 & 0,03 \\
2 & 0,37 & $1,43 \mathrm{~b}$ & 0,86 & 0,02 & 0,02 & 0,03 \\
4 & 0,40 & $1,94 \mathrm{a}$ & 0,89 & 0,03 & 0,02 & 0,03 \\
6 & 0,40 & $2,10 \mathrm{a}$ & 0,59 & 0,03 & 0,02 & 0,03 \\
8 & 0,27 & $2,13 \mathrm{a}$ & 0,91 & 0,02 & 0,03 & 0,04 \\
10 & 0,39 & $1,62 \mathrm{~b}$ & 0,63 & 0,02 & 0,02 & 0,04 \\
\hline F Trat (T) & $0,09^{\text {n.s. }}$ & $1,63^{\text {n.s. }}$ & $3,78^{*}$ & $3,98^{*}$ & $12,39^{*}$ & $11,55^{*}$ \\
F Dist (D) & $0,82^{\text {n.s. }}$ & $2,31^{*}$ & $1,08^{\text {n.s. }}$ & $2,26^{\text {n.s. }}$ & $1,69^{\text {n.s. }}$ & $1,75^{\text {n.s. }}$ \\
F T X D & $1,13^{\text {n.s. }}$ & $0,45^{\text {n.s. }}$ & $0,59^{\text {n.s. }}$ & $1,10^{\text {n.s. }}$ & $1,39^{\text {n.s. }}$ & $1,14^{\text {n.s. }}$ \\
\hline CV1 (\%) & 32,36 & 31,27 & 49,98 & 40,49 & 26,84 & 24,83 \\
CV2 (\%) & 24,16 & 22,97 & 28,84 & 22,58 & 19,28 & 19,18 \\
\hline
\end{tabular}

Médias seguidas de letras iguais não diferem entre si pelo teste de Scott-Knott a $5 \%$ de probabilidade. ${ }^{*}=$ significativo e n.s. = não significativo.

$\mathrm{Na}$ camada de 0,10-0,20 m os maiores valores de resistência à penetração foram nos tratamentos ILP e ILPF 3L, resultados estes semelhantes aos de FERREIRA et al. (2013). Segundo BEUTLER et al. (2001), a resistência mecânica do solo à penetração aumenta com a compactação do solo, restringindo o crescimento radicular das culturas quando esses valores se encontram acima da faixa entre 1,5 a 3,0 MPa, no caso do presente estudo, os valores ficaram abaixo desse nível, indicando que os sistemas integrados podem proporcionar boa estruturação ao solo. 
Nota-se nas camadas de 0-0,05 e 0,10-0,20 m que os valores encontrados para os tratamentos estão menores que 1,1 e 2,5 MPa e na camada de 0,05-0,10 m estão no limite superior dessa faixa e que segundo CANARACHE (1990) apresenta pouca limitação ao crescimento das raízes. Resultados encontrados neste trabalho concordam com DRESCHER et al (2011) que encontraram camadas compactadas na camada de 0,07 a 0,15 m em áreas em sistemas plantio direto, limitando o rendimento das culturas.

Nas SIPAs, a compactação do solo pelo pisoteio animal ainda é uma grande preocupação, apesar dessa problemática ser antiga nos sistemas de produção. Ainda segundo o PORTAL KLFF (2012), a compactação ocasionada por pisoteio é uma preocupação ao solo de produtores, sendo que diversos estudos na literatura evidenciam este processo. De acordo com MARCHÃO et al. (2007) a compactação ocasionada pelo pisoteio animal depende principalmente, da classe do solo, do teor de umidade, da taxa de lotação animal e da espécie de massa forrageira utilizada.

A presença de animais em áreas cultivadas sob o sistema integração lavoura-pecuária pode ocasionar compactação superficial do solo devido ao pisoteio (BALBINOT JUNIOR et al. 2009). MARCHÃO et al. (2009) observaram em solos de textura arenosa a média um pequeno incremento na resistência à penetração, dados estes que concordam com os verificados neste trabalho.

Segundo PORTUGAL (2016) outros fatores também podem ser citados sobre a influência da compactação como a intensidade e frequência de pastejo, peso animal, características intrínsecas do solo, teor de matéria orgânica, cobertura do solo, manejo da pastagem, hábito de crescimento das espécies in loco (entouceiradas ou ramadas) e teor de umidade no solo. Com isso, a determinação da umidade do solo no momento da avaliação da resistência do solo à penetração (BONINI \& ALVES 2012) é fundamental para se realizar adequadamente a interpretação dos resultados encontrados.

Para a umidade gravimétrica do solo, a distância não interferiu, e os tratamentos apresentaram diferenças estatísticas em todas as camadas de solo estudadas. $O$ tratamento ILPF $3 \mathrm{~L}$ obteve valor superior de umidade gravimétrica na camada de 0,05-0,10 m e também valores superiores para o atributo resistência a penetração nas camadas de 0,05-0,10 m e 0,10-0,20 m, resultado este que difere de LIMA et al. (2010), que observaram que quando há uma baixa umidade no solo a resistência à penetração é maior. No presente estudo na camada mais superficial estudada o tratamento bosque, onde há maior densidade de eucalipto comparado aos demais tratamentos, apresenta o menor teor de umidade.

MARCHÃO (2007) verificou que os sistemas integrados de produção agropecuária alteram alguns atributos físico-hídricos do solo, acarretando incremento na resistência à penetração e na densidade do solo pelo pisoteio dos animais durante a fase de pastagem na rotação, porém não prejudicou a produção dos cultivos subsequentes. No estudo desenvolvido, o tratamento ILPF 3L e ILP foram os que apresentaram maiores valores para o atributo resistência à penetração.

Em trabalho realizado por SANTANA et al. (2014), estes verificaram que até $40 \mathrm{~cm}$ de profundidade, a pastagem convencional apresentou menores valores de RP em relação a ILPF. Segundo os mesmos autores na ILPF isso é explicado pela menor umidade, sendo que no sistema essa propriedade física do solo nessas camadas tende a ser menor devido ao consumo de água pelas plantas. No presente trabalho foram obtidos resultados diferentes dos encontrados pelo autor, Na Tabela 1 pode ser verificado que a ILP apresenta maior resistência a penetração comparada ao tratamento ILPF 1L, porém não difere estatisticamente do resultado obtido na ILPF 3L.

$\mathrm{Na}$ camada mais superficial os resultados obtidos mostram que o tratamento bosque (plantio exclusivo de eucalipto) possui menor umidade comparado aos demais tratamentos. Em pesquisa realizada por AGUIAR (2008), a autora afirma que espécies florestais podem reduzir rapidamente a umidade do solo devido alta capacidade de absorção de água do solo, isso pode ser observado principalmente em solos que possuem baixa capacidade de armazenamento de água. Outro aspecto ressaltado pela autora é o fato que espécies florestais interceptam a água das chuvas pela parte aérea e esse fator pode resultar em redução da umidade do solo, já que parte da água é interceptada, reduzindo a disponibilidade de água no solo. Outro fator atribuído ao menor teor de umidade do sistema silvipastoril deve-se à maior drenagem profunda, favorecida pelos macroporos neste sistema, ou ainda à possível maior taxa de evaporação de água do solo, ocasionada por uma menor cobertura vegetal desta área (MENEZES et al. 2013). MARTINKOSKI et al. (2017) verificaram maior microporosidade na área florestal em relação ao sistema manejado, e isso segundo a pesquisa realizada influenciou para que o sistema silvipastoril apresentasse menor capacidade de armazenamento de água.

Nas camadas de solo estudadas ocorreu nenhuma ou pequena variação da umidade do solo entre os tratamentos, o que reforça a interpretação efetuada, uma vez que as diferenças encontradas não estão 
sendo influenciadas pelo conteúdo de água do solo.

Conclui-se que o teor de água no solo não influenciou a resistência à penetração de raízes. A camada superficial não está compactada em todos os tratamentos estudados. Os melhores resultados foram encontrados para o bosque de eucaliptos onde não teve pastejo, tampouco movimentação de maquinário. De modo geral, os resultados mostram que nas condições de solo da região considerados frágeis e altamente susceptíveis a compactação, a presença dos animais não causa uma compactação muito drástica ao solo, com valores menores que o limite crítico de $2 \mathrm{MPa}$.

\section{AGRADECIMENTOS}

Agradecemos a FAPESP pelo apoio financeiro e a concessão de bolsa de iniciação cientifica (PROC FAPESP 2015/21525-0 e 2017/08818-3) e a Agência Paulista de Tecnologia dos Agronegócios (APTA) Polo de Andradina por ceder a área para realização do experimento.

\section{REFERÊNCIAS}

AGUIAR MI. 2008. Qualidade física do solo em sistemas agroflorestais. Dissertação (Mestrado em Solos e Nutrição de Plantas). Viçosa: UFV. 89p.

ALBUQUERQUE JA et al. 2001. Efeito da integração lavoura pecuária nas propriedades físicas do solo e características da cultura do milho. Revista Brasileira de Ciência do Solo 25: 717-723.

BALBINO LC et al. 2011. Evolução tecnológica e arranjos produtivos de sistemas de integração lavoura-pecuáriafloresta no Brasil. Pesquisa Agropecuária Brasileira 46: i-xii.

BALBINOT JUNIOR AA et al 2009. Propriedades físicas em Cambissolo Háplico manejado sob o sistema integração lavoura-pecuária. Revista de Ciências Agroveterinárias 8: 25-34.

BEUTLER AN et al. 2001. Resistência à penetração, permeabilidade de Latossolo Vermelho distrófico típico sob sistemas de manejo na Região dos Cerrados. Revista Brasileira de Ciência do Solo 25: 167-177.

BONINI CSB \& ALVES MC. 2012. Qualidade física de um Latossolo Vermelho em recuperação há dezessete anos. Revista Brasileira de Engenharia Agrícola e Ambiental 16: 329-336.

BONINI CSB et al. 2016. Produção de forragem e atributos químicos e físicos do solo em sistemas integrados de produção agropecuária. Pesquisa Agropecuária Brasileira 51: 1695-1698.

CANARACHE A 1990. PENETR - A generalized semi-empirical model estimating soil resistance to penetration. Soil and Tillage Research 16: 51-70.

COSTA NR et al. 2015. Atributos do solo e acúmulo de carbono na integração lavoura-pecuária em sistema plantio direto. Revista Brasileira de Ciência do Solo 39: 852-863.

DRESCHER MS et al. 2011. Persistência do efeito de intervenções mecânicas para a descompactação de solos sob plantio direto. Revista Brasileira de Ciência do Solo 35: 1713-1722.

FERREIRA AD et al. 2013. Resistência do solo à penetração em diferentes sistemas de integração lavoura-pecuáriafloresta. In: Congresso Sistemas agroflorestais e desenvolvimento sustentável. Anais... Campo Grande: Embrapa. p.16.

FERREIRA DF. 2011. Sisvar: a computer statistical analysis system. Ciência e Agrotecnologia 35: 1039-1042.

GREENWOOD KL \& MCKENZIE BM 2001. Grazing effects on soil physical properties and the consequences for pastures: a review. Australian Journal of Experimental Agriculture 41: 1231-1250.

KLUTHCOUSKI J et al. 2015. Potencial para adoção da estratégia de integração lavoura-pecuária-floresta para o uso sustentável de solos arenosos. In: CORDEIRO LAM et al. (Ed.). Integração lavoura-pecuária-floresta: o produtor pergunta, a Embrapa Responde. Brasília: Embrapa. p.319-331.

LANZANOVA ME et al. 2007. Atributos físicos do solo em sistema de integração lavoura-pecuária sob plantio direto. Revista Brasileira de Ciência do Solo 31: 1131-1140.

LIMA CGR et al. 2010. Atributos físico-químicos de um Latossolo do cerrado brasileiro e sua relação com características dendrométricas do eucalipto. Revista Brasileira de Ciência do Solo 34: 163-173.

MARCHÃO RL. 2007. Integração lavoura-pecuária num Latossolo do Cerrado: impacto na física, matéria orgânica e macrofauna. Tese (Doutorado em Agronomia). UFG: Goiânia. 153p.

MARCHÃO RL et al. 2007. Qualidade física de um Latossolo Vermelho sob sistemas de integração lavoura-pecuária no Cerrado. Pesquisa Agropecuária Brasileira 42: 873-882.

MARCHÃO RL et al. 2009. Impacto do Pisoteio Animal na Compactação do Solo sob Integração Lavoura-Pecuária no Oeste Baiano. Planatina: Embrapa. 6p. (Comunicado técnico 163).

MARTINKOSKI L et al. 2017. Qualidade física do solo sob manejo silvipastoril e floresta secundária. Revista Floresta e Ambiente 24: 1-9.

MENEZES JAL et al. 2013. Comportamento temporal da umidade do solo sob Caatinga e solo descoberto na Bacia Experimental do Jatobá, Pernambuco. Water Resources and Irrigation Management 2: 45-51.

PIGNATARO NETTO I et al. 2009. Atributos físicos e químicos de um Latossolo vermelho-amarelo sob pastagens com diferentes históricos de uso. Revista Brasileira Ciência do Solo 33: 1441-1448.

PORTAL KLFF. 2012. Compactação do Solo por Pisoteio Animal. Disponível em: http://www.portalklff.com.br/publicacao/oldlink-1051. Acesso em: 10 jun. 2019. 
PORTUGAL NRN. 2016. Compactação do solo por atividades agropecuárias. Monografia (Especialização em Tecnologia em Gestão Ambiental). Ariquemes: Faculdade de Educação e Meio Ambiente. 27p.

REICHERT JM et al. 2007. Compactação do solo em sistemas agropecuários e florestais: identificação, efeitos, limites críticos e mitigação. In: CERETTA CA et al. (Ed.) Tópicos em ciência do solo. Viçosa: SBCS. p.49-134.

SÁ MAC et al. 2007. Compactação do solo e produtividade da cultura da soja em área irrigada no Cerrado. Planaltina: Embrapa. 31p. (Boletim de pesquisa e desenvolvimento 177).

SANTANA AV et al. 2014. Resistência a penetração em solo sob sistema integração lavoura-pecuária floresta, pasto convencional e mata nativa do cerrado. Enciclopédia Biosfera 10: 2675-2680.

SANTOS HG et al. 2018. Sistema de Classificação de Solos. 5.ed. Brasília: Embrapa Solos. 355p.

SILVA GF et al. 2015. Indicadores de qualidade do solo sob diferentes sistemas de uso na mesorregião do agreste paraibano. Revista Caatinga 28: 25-35.

TAVARES FILHO J \& RIBON AA. 2008. Resistência do solo à penetração em resposta ao número de amostras e tipo de amostragem. Revista Brasileira de Ciência do Solo 32: 487-494.

TAVARES FILHO J et al. 2005. Compressibilidade de agregados de um Latossolo Amarelo da Amazônia em resposta ao potencial da água do solo. Revista Brasileira de Ciência do Solo 29: 489-495.

TEIXEIRA PC et al. 2017. Manual de métodos de análise de solo. 3.ed. Brasília: Embrapa Solos. 573p. 